\title{
Human-Plant Coevolution: A modelling framework for theory-building on the origins of agriculture
}

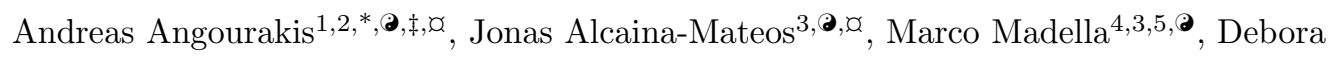
Zurro $^{6, \odot}$

1 McDonald Institute for Archaeological Research, University of Cambridge, Cambridge, United Kingdom

2 Institut für Archäologische Wissenschaften, Ruhr Universität Bochum, Bochum, Germany

3 CaSEs, Department of Humanities, Universitat Pompeu Fabra, Barcelona, Spain 4 Institució Catalana de Recerca i Estudis Avançats (ICREA), Barcelona, Spain 5 School of Geography, Archaeology and Environmental Studies, The University of the Witwatersrand, Johannesburg, South Africa

6 HUMANE - Human Ecology and Archaeology Research Group, Departamento de Arqueología y Antropología, Institución Milá y Fontanals de Investigación en Humanidades - Consejo Superior de Investigaciones Científicas (CSIC), Barcelona, Spain

DThese authors contributed equally to the text.

$\ddagger$ This authors contributed with initial model concept and prototype.

QThese authors contributed with later version of the model, simulation experiments and statistical analyses.

* aa2112cantab.ac.uk; andros.spica@gmail.com

\section{Abstract}

The domestication of plants and the origin of agricultural societies has been the focus of much theoretical discussion on why, how, when, and where these happened. The 'when' and 'where' have been substantially addressed by bioarchaeology, thanks to advances in 
methodology and the broadening of the geographical and chronological scope of evidence. However, the 'why' and 'how' have lagged behind, holding on to relatively old models with limited explanatory power. Armed with the evidence now available, we can return to theory by revisiting the mechanisms allegedly involved, disentangling their connection to the diversity of trajectories, and identifying the weight and role of the parameters involved. We present the Human-Plant Coevolution (HPC) model, which represents the dynamics of coevolution between a human and a plant population. The model consists of an ecological positive feedback system (mutualism), which can be reinforced by positive evolutionary feedback (coevolution). The model formulation is the result of wiring together relatively simple simulation models of population ecology and evolution, through a computational implementation in R. The HPC model captures a variety of potential scenarios, though which conditions are linked to the degree and timing of population change and the intensity of selective pressures. Our results confirm that the possible trajectories leading to neolithisation are diverse and involve multiple factors. However, simulations also show how some of those factors are entangled, what are their effects on human and plant populations under different conditions, and what might be the main causes fostering agriculture and domestication.

\section{Introduction}

The domestication of plants and the origin of agriculture is a major change in human history, and it has been the focus of much theoretical discussion on why, how, when and where this change happened. Evidence from archaeobotany and plant genomics gathered during the last two decades expanded our knowledge on where this process happened and identified several centres of agricultural origin around the world [1-3]. Methodological advances in identification criteria [4] and the widespread recovery of plant remains from archaeological sites [5] better clarified the timing of this process in many areas. However, the why and how seems to lag behind in comparison [6-8].

Climate change [9-11], cognitive/symbolic change [12-14], or social competition and demography $[15,16]$ have long been discussed as drivers for socio-ecological transformations called the Neolithic Revolution [17]. A major problem with these approaches is to bundle under the same explanation behavioural trajectories that do not 
necessarily share the same premises. Domestication and agriculture emerged from diverse historical contexts and the empirical record available is manifold and often contradictory in evidencing causality [18]. Furthermore, many models rely on ethnographic observations of contemporary traditional practices among indigenous peoples around the world, practices that may greatly differ in context from those of the first communities to engage in agriculture within a given region [19-23].

A current and lively discourse on how domestication (and eventually agriculture) came into being is that of protracted [24-27] versus expedite $[14,28]$ domestication. Broad contextual analyses of the archaeobotanical record within macroevolutionary theory [18] and single-crop approaches [29] started to bring new light on the process of domestication based on a fast-growing body of archaeological evidence. The analysis of this massive and relatively recent volume of data makes clear that it is now necessary to return to theory by revisiting the mechanisms allegedly involved in domestication, disentangling their connection to a diversity of trajectories [30], being those protracted or sudden, and identifying the weight of the social and ecological parameters.

Approaches developed within human behavioural ecology have gained momentum in this effort [31-35], such as niche construction or cultural niche construction theories. These approaches emphasise "the capacity of organisms to modify natural selection in their environment and thereby act as co-directors of their own, and other species', evolution" [36]. However, such perspectives have been heavily criticised, among other points, based on them being presumably indifferent to the role of human agency and intentionality $[14,28,37,38]$. The relevant, yet stale, century-long debate on human intentionality in plant domestication is one clear sign that the field still lacks a unifying theoretical framework.

\section{Simulation approaches to human-plant coevolution}

The study of prehistoric human past is necessarily approached through archaeological materials, which do not always allow addressing historical processes and organizational dynamics. Information gaps as well as uncertainty have pushed forward archaeology within the historical sciences to participate in innovative methodologies and approaches such as modelling and simulation. In subjects as domestication and the origins of 
agriculture, where the archaeological record is incomplete in both space and time, and real-world experiments are unrealistic, the use of modelling and simulation has become a useful alternative for testing hypotheses and building theory [39]. However, the most exemplary contributions within these lines have focus on the representation of plant domestication in terms of genetic change $[24,40]$ and the geographical spread of the Neolithic transition [41-44], mainly for testing hypotheses related to regional or species-wise case studies. Exceptionally, there have been important contributions from niche construction and optimal foraging theories, however strictly from the human perspective [45-47]. Few, if any, have addressed the core mechanism that could produce changes in both plants and humans.

The current work is a contribution to explore hypotheses on plant domestication and the origin of agriculture by using a coevolutionary framework capable of accounting for both plant and human factors. Our model combines readily-available formal models for mutualism and evolution used in population ecology, sociology and economics. We state our assumptions explicitly and have worked intensively on documenting all model details to assure its reproducibility and facilitate re-use and future expansions. Our contribution is theoretical and explorative, thus not driven by any specific dataset or case study. It does not carry the pretence - in its current form - of direct applicability to the many formats of empirical data.

\section{The Human-Plant Coevolution (HPC) model}

Human-plant interaction is a specific case of animal-plant interaction, which spans from predator-prey to mutualistic and symbiotic relationships. All ecological relationships consistent in time are driven by coevolution, where each party exerts selective pressures on the other, eventually redefining their genetic (and cultural) construct [48-50] [51]. Under mutualistic coevolution, the interaction between two populations increases the total potential return or carrying capacity of the environment for each species. At the same time, it also modifies the selective pressures acting over the populations involved. In this light, plant domestication is similar to other mutualistic relationships, where coevolution produced the emergence of certain traits, manifested at physiological, morphological and behavioural levels; e.g., insects and fungi [52] and ants and 
acacia [53].

The Human-Plant Coevolution (HPC) model is an ecological positive feedback system (mutualism), which can be reinforced by an evolutionary positive feedback (coevolution). The model is the result of wiring together relatively simple models of population ecology (Verhulst-Pearl model) and evolution (replicator dynamics), through a computational implementation using $\mathrm{R}$ programming language [54].

The HPC model embodies the dynamics of two interacting populations: one of humans and another of a given plant species. Here, we assume that population units are individual organisms. Because this model greatly simplifies the mechanisms involved in population dynamics, units could also be set to be groups of individuals or even population proxies (e.g. human working hours, plant-covered soil surface). However, the scale of population units is relevant when calibrating parameters and interpreting results, and thus must be made explicit.

Each population unit may exploit the available resources in different ways, and may have a different utility for sustaining the other population. To represent this, we assume that each population can be divided into types ranging from the least (1) to the most (n) mutualistic, each corresponding to a value of baseline carrying capacity and utility per capita, which in turn range from population-specific minima and maxima. Each type can relate either to truly discrete units (e.g., presence/absence of trait), arbitrary degrees in a continuum (e.g., size of anatomy trait, frequency of behaviour), or a combination of both. In the case of human populations, types would consist majorly of different combinations of behaviours impacting the plant population, such as protection from predators, removal of competitors, enhancement of soil conditions, or transporting and storing propagules.

This simplification of population diversity gives the possibility to implement a relatively simple and straightforward mechanism of evolution, the replicator dynamics [55]. Under our specific version of this mechanism, the distribution of a population within types changes depending on three factors: (1) undirected variation, (2) inertia, and (3) selection.

The HPC model was conceptualised as a highly symmetric structure (Fig ??). This model reduces the complexity of the human and plant populations to a point where these can be defined using the same terms (parameters and variables). The symmetry is 
only broken by the inclusion of a constraint specific to plants, the maximum number of

106 plant units fitting the area available (MaxArea), reflecting one of the main ecological differences between plants and animals: the latter are able to move and exploit multiple habitats within a lifetime.

The HPC model enables to reproduce a double positive feedback loop, where two populations increase their carrying capacity (mutualism) and empower this relationship by influencing each other's trait selection (coevolution). The consequence is that, given certain conditions, both human and plant populations shift to stronger mutualism types and increase their numbers, potentially moving far away from pre-coevolutionary levels (Fig ??).

All parameters and variables of the model are listed and defined in Tables 1 and 2, respectively. States of the system are evaluated and compared by a set of output variables, i.e. those not used to recalculate the state of the system (Table 3). Among the output variables, the coevolution coefficients are the most revealing. Each indicates if and how much the population type distribution has been modified by the coevolutionary process. Their values range between -1 (the entire population is of type 1) and 1 (the entire population is of type $n$ ).

Table 1. Parameters

\begin{tabular}{|l|l|l|}
\hline R notation & Math. notation & Description \\
\hline iniH, iniP & ini $_{H}$, ini $_{P}$ & initial populations of humans and plants \\
\hline n.H, n.P & $n_{H}, n_{P}$ & number of types of humans and plants \\
v.H, v.P & $v_{H}, v_{P}$ & level of undirected variation in humans and plants \\
\hline r.H, r.P & $r_{H}, r_{P}$ & intrinsic growth rates for human and plant populations \\
\hline mU.PnH & $\bar{U}_{P_{n} H}$ & utility per capita of type $n$ plants to humans \\
\hline mU.HnP & $U_{H_{n} P}$ & utility per capita of type $n$ humans to plants \\
\hline mU.P1H & $U_{P_{n} H}$ & utility per capita of type 1 plants to humans \\
\hline mU.H1P & $U_{H_{n} P}$ & utility per capita of type 1 humans to plants \\
\hline U.bPn & $U_{P_{n} H}$ & utility of other resources to type $n$ plants \\
\hline U.bHn & $U_{H_{n} P}$ & utility of other resources to type $n$ humans \\
\hline U.bP1 & $U_{P_{n} H}$ & utility of other resources to type 1 plants \\
\hline U.bH1 & $U_{H_{n} P}$ & utility of other resources to type 1 humans \\
\hline MaxArea & MaxArea & maximum number of plant population units fitting the contiguous area available \\
\hline
\end{tabular}

\section{Ecological relationships and population dynamics}

The model can be expressed by a relatively simple system of two discrete-time difference equations (1), based on the Verhulst-Pearl Logistic equation $[56,57]$. The change of both

(1)

(1)


Table 2. Variables

\begin{tabular}{|l|l|l|}
\hline R notation & Math. notation & Description \\
\hline H, P & $H[t], P[t]$ & Human and plant populations \\
\hline K.H, K.P & $K_{H}[t], K_{P}[t]$ & Carrying capacity to human and plant populations \\
\hline U.HP, U.PH & $U_{H P}[t], U_{P H}[t]$ & Utility of one population to the other \\
\hline U.bH, U.bP & $U_{b H}[t], U_{b P}[t]$ & intrinsic growth rates for human and plant populations \\
\hline types.H, types.P & types, types & Population types, arbitrarily ordered from 1 to $n$ (vector) \\
\hline pop.H, pop.P & $p o p_{H}[t]$, pop $_{P}[t]$ & Proportion of a population belonging to type $i$ (vector) \\
\hline $\begin{array}{l}\text { mU.HP.per.type, } \\
\text { mU.PH.per.type }\end{array}$ & $U_{H_{i} P}, U_{P_{i} H}$ & $\begin{array}{l}\text { Utility per capita of type } i \text { individuals of one population to the } \\
\text { other (vector) }\end{array}$ \\
\hline $\begin{array}{l}\text { U.bH.per.type } \\
\text { U.bP.per.type }\end{array}$ & $\bar{U}_{b H_{i}}, \bar{U}_{b P_{i}}$ & $\begin{array}{l}\text { Utility of other resources to type } i \text { individuals of a population } \\
\text { (vector) }\end{array}$ \\
\hline $\begin{array}{l}\text { fitness.H, } \\
\text { fitness.P }\end{array}$ & fitness $s_{H}[t]$, fitness $P[t]$ & Fitness score of type $i$ individuals of a population (vector) \\
\hline d.H, d.P & $\Delta H[t], \Delta P[t]$ & Population change at time t (vector) \\
\hline
\end{tabular}

Table 3. Variables (output only)

\begin{tabular}{|l|l|l|}
\hline R notation & Math. notation & Description \\
\hline $\begin{array}{l}\text { coevo.H, } \\
\text { coevo.P }\end{array}$ & coevo $_{H}[t]$, coevo $_{P}[t]$ & $\begin{array}{l}\text { Coevolution coefficient or the distribution of the proportions of } \\
\text { a population per type weighted by type index }\end{array}$ \\
\hline $\begin{array}{l}\text { depend.H, } \\
\text { depend.P }\end{array}$ & depend $_{H}[t]$, depend $_{P}[t]$ & $\begin{array}{l}\text { Dependency coefficient or the slope of the linear model of the } \\
\text { fitness score per type ( fitness } A_{1} \text { to } \text { fitness }_{A_{n}} \text { ) using type } \\
\text { index }(1 \text { to } n)\end{array}$ \\
\hline $\begin{array}{l}\text { timing.H, } \\
\text { timing.P }\end{array}$ & timing $_{H}[t]$, timing $_{P}[t]$ & $\begin{array}{l}\text { Iterations past until coevolution successfully changes the pro- } \\
\text { portions of population per type }\end{array}$ \\
\hline time & $t_{\text {end }}$ & Iterations past until the end-state \\
\hline
\end{tabular}

populations $(\Delta H[t], \Delta P[t]$; see Table 2$)$ depends on an intrinsic growth rate $\left(r_{H}, r_{P}\right)$, the population at a given time $(H[t], P[t])$ and the respective carrying capacity of the environment for each population $\left(K_{H}[t], K_{P}[t]\right)$, which may vary over time.

$$
\begin{gathered}
H[t+1]=H[t]+r_{H} H[t]-r_{H} \frac{H[t]^{2}}{K_{H}[t]} \\
P[t+1]=P[t]+r_{P} P[t]-r_{P} \frac{P[t]^{2}}{K_{P}[t]}
\end{gathered}
$$

Human and plant populations engage in a mutualistic relationship, where one species is to some extent sustained by the other (2). The mutualistic relationship is defined in the model as an increment of the carrying capacity of population B caused by population $\mathrm{A}\left(U_{A B}[t]\right)$. This increment, expressed as the utility of $\mathrm{A}$ to $\mathrm{B}$ at a given time, is the product of the utility per capita of $\mathrm{A}$ to $\mathrm{B}\left(\bar{U}_{A B}\right)$ and the population $\mathrm{A}$ at a given time (3). 
We consider that both populations are sustained also by an independent term, representing the baseline carrying capacity of the environment or the utility gain from other resources, which is time-dependent $\left(U_{b H}[t], U_{b P}[t]\right)$. While we assume that the growth of the human population has no predefined ceiling, the expansion of the plant population is considered limited as the area over which plants can grow contiguously (MaxArea), and represented as a compendium of both space and the maximum energy available in a discrete location $(2 \mathrm{~b})$.

$$
\begin{array}{r}
K_{H}[t]=U_{P H}[t]+U_{b H}[t] \\
K_{P}[t]=\min \left(U_{H P}[t]+U_{b P}[t], \text { MaxArea }\right) \\
U_{A B}[t]=A[t] \cdot \bar{U}_{A B}
\end{array}
$$

Considering that mutualistic relationships involve a positive feedback loop, the population growth at time $t$ improves the conditions for both humans and plants at time $t+1$, sustaining their growth even further. See model assumptions in Table 4 .

\section{Population diversity}

The HPC model contemplates a vector ( $p o p)$ of length $n$, containing the population fractions of each type. The number of types is population-specific and are given as two parameters $\left(n_{H}, n_{P}\right)$. These types include all possible variations within a population so that this vector amounts to unity $\left(\sum_{i=1}^{n}\right.$ pop $\left._{i}=1\right)$.

To account for multiple types, we replace (3) with (4), where the utility of population $\mathrm{A}$ to $\mathrm{B}$ at any given time $\left(U_{A B}[t]\right)$ is calculated by summing up the utility per capita of each type $\left(\bar{U}_{A_{i} B}\right)$ proportionally to the share of population of the respective type $\left(\operatorname{pop}_{A_{i}}[t]\right)$, and multiplying the result by the population at a given time. The baseline carrying capacity $\left(U_{b A_{i}}[t]\right)$ is calculated similarly, though using the utility that each type is able to gain from other resources $\left(U_{b A_{i}}\right)(5)$.

$$
U_{A B}[t]=A[t] \sum_{i=1}^{n_{A}} \operatorname{pop}_{A_{i}}[t] \cdot \bar{U}_{A_{i} B}
$$


Table 4. Assumptions on ecological relationships and population dynamics

\begin{tabular}{|c|c|}
\hline Domains & Assumptions \\
\hline On interacting populations & A population of humans interacts with a population of plants. \\
\hline On population growth & $\begin{array}{l}\text { Population growth is a self-catalysing process, where the population density } \\
\text { in the present will contribute to its own increase in the future, depending } \\
\text { on an intrinsic growth rate }(r) \text {. } \\
\text { Population growth is a self-limiting process, where the population density } \\
\text { in the present will constraint its own increase in the future, depending on } \\
\text { respective carrying capacity of the environment }(K) \text {. } \\
\text { The logistic growth model is acceptable as an approximation to the dynamics } \\
\text { of populations, both human and plant, under constant conditions. } \\
\text { The carrying capacity of the environment for a population depends on } \\
\text { constant factors and on a time-varying factor }(K[t]) \text {. }\end{array}$ \\
\hline On positive ecological relationships & $\begin{array}{l}\text { Positive ecological relationships exist, where an individual of one population } \\
\text { increases by an amount the carrying capacity of the environment for another } \\
\text { population. } \\
\text { Coupled positive ecological relationships (i.e., mutualism) exist, where two } \\
\text { populations increase the carrying capacities for each other. } \\
\text { There is variation in positive ecological relationships, so individuals of one } \\
\text { population vary in terms of how much they increase the carrying capacity } \\
\text { for the other population. }\end{array}$ \\
\hline On human-plant mutualism & $\begin{array}{l}\text { A given plant species yield a positive utility for humans, e.g., as a source of } \\
\text { food and raw materials. } \\
\text { Humans return a positive utility for this plant species, e.g., by improving } \\
\text { soil conditions. } \\
\text { The utility given by one population adds value to the carrying capacity for } \\
\text { the other, and vice versa. } \\
\text { The carrying capacity for humans rely also on other resources, which are } \\
\text { independent of the plant species (i.e., the baseline carrying capacity for } \\
\text { humans). } \\
\text { The carrying capacity for plants also rely on other conditions, which are } \\
\text { independent of humans (i.e., the baseline carrying capacity for plants). } \\
\text { The carrying capacity for plants is eventually constrained by the space } \\
\text { available for it to grow contiguously as a population (i.e., maximum area). }\end{array}$ \\
\hline
\end{tabular}

$$
U_{b A}[t]=\sum_{i=1}^{n_{A}} \operatorname{pop}_{A_{i}}[t] \cdot U_{b A_{i}}
$$

Types relate to population-specific values of utility per capita $\left(\bar{U}_{A_{i} B}\right)$ and baseline carrying capacity $\left(U_{b A_{i}}\right)$. These values are defined by linear interpolation between pairs of parameters representing the values corresponding to types 1 and $n$ (e.g., if $n_{P}=10$, $\bar{U}_{P_{1} H}=1$ and $\bar{U}_{P_{n} H}=10$, then $\left.\bar{U}_{P_{5} H}=5\right)$. The shares of population within types follow a one-tail distribution rather than a normal distribution, which would be more adequate but less straightforward to use in a theoretical model. Under this circumstance, the distribution of population within types will always be biased towards the intermediate types. 


\section{Coevolutionary dynamics}

Undirected variation, which causes part of the population to randomly change to other $\quad{ }_{165}$ types, represents the effect of mutation in genetic transmission or of innovation, error, $\quad{ }_{166}$ and other mechanisms in cultural transmission. The balance of the subpopulation A of ${ }_{167}$ type $i$ depends on the level of undirected variation $\left(v_{A}\right)$ and on the degree and sign of the difference between the current subpopulation $\left(\operatorname{pop}_{A_{i}}[t]\right)$ and the averaged subpopulation $\left(1 / n_{A}\right)$, which refers to the completely uniform distribution among types (6).

$$
\operatorname{pop}_{A}[t]^{\prime}=\operatorname{pop}_{A}[t]+v_{A}\left(\frac{1}{n_{A}}-\operatorname{pop}_{A}[t]\right)
$$

By considering inertia, we are assuming that the more frequent a type is, the more likely that it is transmitted. Selection is implemented by assigning a fitness score to each type ( fitness $_{A_{i}}[t]$ ), which in turn biases its transmission. (7) summarizes the combined effect that inertia and selection have on the proportion of population $\mathrm{A}$ belonging to type $i\left(\operatorname{pop}_{A_{i}}[t]\right)$; for a formal similarity of the discrete replicator dynamic and Bayesian inference, see [58].

$$
\operatorname{pop}_{A_{i}}[t+1]=\frac{\text { fitness }_{A_{i}}[t] \cdot \operatorname{pop}_{A_{i}}[t]}{\sum_{j=1}^{n_{A}} \operatorname{fitness}_{A_{j}}[t] \cdot \operatorname{pop}_{A_{j}}[t]}
$$

This mechanism defines how a trait evolves in a single population. However, coevolution can also be represented when the selective pressure on this population is modified by the changing traits of another population. In order to link the two populations, fitness scores of population A are derived from the weight of the contribution or utility of population $\mathrm{B}\left(U_{B A}[t]\right)$ in relation to the base carrying capacity of $\mathrm{A}\left(K_{A}[t]\right)(8)$

$$
\text { fitness }_{A_{i}}[t]=\frac{\left(n_{A}-i\right) U_{b A}[t]+i U_{B A}[t]}{U_{b A}[t]+U_{B A}[t]}
$$

As a consequence of this model design, types of both human and plant populations span from a non-mutualistic type $(i=1)$, which has the best fitness score when there is no positive interaction with the other population $\left(U_{B A}[t] \approx 0\right)$, to a mutualistic type $(i=n)$, which is the optimum when nearly the whole of the carrying capacity is due to 
Table 5. Assumptions on population diversity and coevolution

\begin{tabular}{|l|l|}
\hline Domains & Assumptions \\
\hline On the evolution of traits & $\begin{array}{l}\text { A population can be divided into types according to one or more traits. } \\
\text { The distribution of individuals among types can vary in time, due to factors } \\
\text { affecting trait transmission. }\end{array}$ \\
\hline $\begin{array}{l}\text { On the factors affecting the evolution } \\
\text { of traits }\end{array}$ & $\begin{array}{l}\text { Change of the population distribution among types depends on the previous } \\
\text { population distribution: the more frequent is a type, the more likely it will } \\
\text { be imitated or transmitted to the next generation. } \\
\text { Change of the population distribution among types depends on the relative } \\
\text { fitness of types: the greater the fitness score associated to a type, the more } \\
\text { likely it will be imitated or transmitted to the next generation. } \\
\text { Change of the population distribution among types depends on undirected } \\
\text { variation. }\end{array}$ \\
\hline $\begin{array}{l}\text { On the coevolution of traits related } \\
\text { to human-plant mutualism }\end{array}$ & $\begin{array}{l}\text { The utility given by an individual varies within types. } \\
\text { The utility given by other resources to a population varies within its types. } \\
\text { The fitness of human types is modified by the relative weight of plant utility } \\
\text { in the carrying capacity for humans } \\
\text { The fitness of plant types is modified to the relative weight of human utility } \\
\text { in the carrying capacity for plants. }\end{array}$ \\
\hline
\end{tabular}

\section{End-states}

A simulation ends when both populations and their respective type distributions are stable; i.e. no further change occurs given current conditions. More specifically, a state is considered stable when the difference in variables between time $t$ and $t-1$ is very small (e.g. less than $10 e^{-6}$ ). End-states defined by unchanged variables are known as stationary points. Exceptionally, under certain parameter settings, the HPC model does not converge into a stationary point but enters an oscillatory state. To handle these rare cases and others producing extremely slow-paced dynamics, simulations are interrupted regardless of the conditions after a certain number of iterations ('maxIter', in the implementation in R).

\section{Output variables}

The most important output variables are the coevolution coefficients $\left(\right.$ coevo $_{H}$, coevo $\left._{P}\right)$, which measure the trend in the distribution of a population among its types (9).

$$
\operatorname{coevo}_{A}[t]=\frac{\left.\sum_{i=1}^{n_{A}} \operatorname{pop}_{A_{i}}[t] *\left(\text { types }_{A_{i}}-1\right)\right)}{n_{A}-1} * 2-1
$$


The dependency coefficients $\left(\right.$ depend $_{H}$, depend $\left._{P}\right)$ express the direction and intensity 202 of the selective pressure caused by the other population. It is calculated as the slope coefficient of a linear model of the fitness scores $\left(\right.$ fitness $\left._{A}[t]\right)$ using the type indexes $\left(\right.$ types $\left._{A}\right)$ as an independent variable.

Positive values of both these coefficients reflect the tendency of a population towards the most mutualistic types (effective coevolution), while negative values indicate an inclination towards the non-mutualistic type due to a low selective pressure exerted by the mutualistic relationship.

We recorded the time step at the end of simulations $\left(\right.$ time $\left._{\text {end }}\right)$, obtaining a measure of the overall duration of the process. Whenever applicable, we register the duration of change towards stronger mutualism types in both populations $\left(\right.$ timing $_{H}$, timing $\left._{P}\right)$. We consider change to be effective when the respective coevolution coefficient is greater than 0.5 ('timing-threshold', in the implementation in R), meaning that at least half of the population is concentrated on the higher quarter of the type spectrum (i.e. from -1 to 1$)$.

\section{Experimental design}

Although relatively simple, the HPC model has a total of 17 parameters. We did not 218 engage in fixing any of these parameters to fit a particular case study as a strategy to $\quad{ }_{219}$ reduce the complexity of results. In turn, as our aim is to explore theoretical grounds, ${ }_{220}$ we scrutinised the 'multiverse' of scenarios that potentially represent the relationship ${ }_{221}$ between any given human population and any given plant species. The complexity of ${ }_{222}$ the model was managed by exploring the parameter space progressively, observing the multiplicity of cases in single runs, two and four-parameter explorations, and an extensive exploration including 15 parameters (all, except $i n i_{H}$ and $i n i_{P}$ ). The latter type of exploration was performed by simulating 10,000 parameter settings sampled with the Latin Hypercube Sampling (LHS) technique [59] and Strauss optimization [60]. All simulation runs were executed for a maximum of 5,000 time steps. 


\section{Model implementation and additional materials}

The source files associated with the HPC model are maintained at a dedicated online repository [61]: https://doi.org/10.5281/zenodo.3881915. This repository contains several additional materials, including a web application to run simulations and the full report on the sensitivity analysis.

The Human-Plant Coevolution model can generate trajectories with or without the successful occurrence of human-plant coevolution. Moreover, simulations revealed a broad spectrum of cases (Fig ??), including those where coevolution produces oscillatory or asymmetric change.

Throughout all conditions explored, the results show that a completely successful coevolutionary trajectory, where both populations effectively change, is relatively demanding and can be deemed unlikely, considering the entirety of the parameter space explored. Furthermore, in light of these results, plant populations are systematically more sensitive to the selective pressure of mutualism than humans, arguing for the scarcity of cases of origins of agriculture in comparison to a relative abundance of effective domestication processes.

\section{End-states}

The wide variety of end-states produced by the HPC model can be classified in three general groups:

- Coevolution does not occur. Simulation runs in which a stationary point is reached without successful coevolution, thus returning a stable state where humans and plants have a weak mutualistic relationship.

- Coevolution occurs. Both populations go through successful coevolution and become stable only once they have shifted towards stronger mutualism types.

- Coevolution occurs partially, encompassing two types of end-states:

- Stationary suboptimal mutualism: One or both populations undergo a significant, but partial change, remaining relatively well distributed among types, or 
- Oscillatory coevolution: Both populations become trapped in an endless cycle $\quad 257$ alternating engagement (strong mutualism) and release (weak mutualism). $\quad 258$

\section{Coevolution does not occur}

Under some conditions, equilibrium is reached without coevolution taking place and consequently both human and plant populations are kept at relatively low densities (Fig ??). Without coevolution, the plant population exists mainly in the non-anthropic niche $\left(U_{b P} \gg U_{H P}\right)$ and in wild forms $\left(\right.$ oop $_{P_{1}} \gg$ pop $\left._{P_{n}}\right)$, while the bulk of human subsistence comes from other resources and only marginally from gathering these plants $\left(U_{b H} \gg U_{P H}\right)$, which most humans do opportunistically and with little impact $\left(\right.$ fitness $_{P_{1}} \gg$ fitness $\left._{P_{n}}\right)$. End-states of this type can still diverge significantly due to different parameter settings.

\section{Coevolution occurs}

As intended, the HPC model is able to generate trajectories where equilibrium is reached with coevolution and mutualism between humans and plants is reinforced (Fig ??; Animation 2). The plant population relies more on the human contribution

$\left(U_{b P} \ll U_{H P}\right)$ and humans depend significantly on harvesting these plants $\left(U_{b H} \ll U_{P H}\right)$.

As a general rule, the coevolved human and plant populations reach higher levels compared to their counterparts in non-coevolutionary end-states under similar conditions. The total contribution from one population to the other will increase when coevolution happens, because of the positive feedback loop between population numbers: i.e. the more humans, more plants, and vice-versa.

In most cases where coevolution happens, the difference between the pseudo-stable and stable population levels before and after coevolution is fairly clear. These two levels are visible as the first and second plateaus in the double-sigmoid curve (see population plot in Fig ??, top left). The steep slope that mediates between these two levels follows the change in the distribution of types, from one centred in type 1 to one centred in type $n$ (in Fig ??, a rightward movement in the top-right plots and upwards in the coevolution curves at the bottom left).

The coevolutionary trajectories can be divided into two phases: 
- Prior to coevolutionary shift: This is a period during which human and plant populations are effectively coevolving. During this phase, population levels approach their first plateau or pseudo-stable state value before coevolution takes effect while the distribution of types change - first slowly, then abruptly — towards the most mutualistic type. It ends when the change in the distribution of types can be considered completed in both populations; we define this moment to be the latest time step between timing $_{H}$ and timing $_{P}$ (in Fig ??, it is timing represented by the pink vertical dashed line).

- Following coevolutionary shift: This is a period characterized by the stabilization of the populations around the truly-stable state. During this phase, both populations can be considered "changed" or effectively coevolved, even though they have still not realised the full potential for population growth made possible by coevolution. Although, depending on the specific conditions set by parameters, this phase typically involves a 'boom' for one or both populations.

Under some conditions, coevolutionary trajectories can display a punctual decrease in carrying capacities towards the end of the first phase, during the change from the least to the most mutualistic types. These demographic "bumps" happen in a population when the stronger mutualism type is less capable of exploiting other resources than the least mutualistic type (i.e., if $U_{b A_{1}}>U_{b A_{n}}$, then $U_{b A}[t]>U_{b A}[t+1]$ during coevolution), while the other population has still not grown enough to counterbalance the loss in carrying capacity. In the example given in Fig ??, the plant population is the one suffering this effect, starting at the vicinity of the shift of the human population (vertical dashed cyan lines). In this case, the most mutualistic plant type is far less capable of exploiting non-anthropic resources than the least mutualistic type $\left(U_{b P_{1}}=100, U_{b P_{n}}=20\right)$ and the utility given by the human population at that point $\left(U_{H P} \approx 80\right)$ lies below the utility obtained from other resources when the least mutualistic types were the vast majority $\left(U_{b P}[t] \approx 100\right.$, for $\left.t=[1,200]\right)$.

\section{Coevolution occurs partially}

Simulation experiments revealed cases in which the coevolution towards stronger mutualism occurs only partially. These cases are relatively rare, considering the entirety 
of the parameter space explored. However, they illustrate the complexity of the interaction of some factors accounted for in the HPC model.

The two types of end-states that fall into this general category, stationary suboptimal mutualism and oscillatory coevolution, are produced under parameter configurations that generally contain strong asymmetries either between the population or between types within the same population. These asymmetries include, for instance, 322 configurations where one population has the most mutualistic types contributing the ${ }_{323}$ same amount of utility per capita than the least mutualistic types $\left(\bar{U}_{A_{1} B}=\bar{U}_{A_{n} B}\right)$. In $\quad{ }^{324}$ this scenario, the positive feedback between population growth and change in the distribution of types is weakened, but only enough to impede the change in one population; this is the case of the settings shown in Fig ?? $\left(\bar{U}_{H_{1} P}=\bar{U}_{H_{n} P}=0.5\right)$.

\section{Parameter explorations}

The extensive exploration of parameters demonstrated that a multiplicity of factors

should be controlled when approaching plant domestication and the origins of agriculture. However, results also shed light into the relative importance of each of the factors included in the model.

We summarise the roles of the parameters of the model as 'facilitators', 'obstructors', and 'scalers'. Under most conditions, increasing the values of any facilitator improves the chances of having a successful coevolution, while greater values in obstructors will diminish it (respectively, positive and negative correlations with $\operatorname{coevo}_{H}, \operatorname{coevo}_{P}$, or with depend $d_{H}$, and depend $\left.d_{P}\right)$. Scalers vary the size of population $(H$ and $P)$ at the end-state and the duration of the processes $\left(\right.$ time $_{e n d}$, timing $_{H}$, and timing $\left._{P}\right)$. Some parameters fit in more than one of the above classes, depending on the setting of the other parameters. The initial populations $\left(i n i_{H}, i n i_{P}\right)$ remain outside this classification, having virtually no effect on end-states.

Parameters are distributed as follows:

- Facilitators: number of types $\left(n_{H}, n_{P}\right)$, undirected variation $\left(v_{H}, v_{P}\right)$, utility per capita to the other population $\left(\bar{U}_{H_{1} P}, \bar{U}_{H_{n} P}, \bar{U}_{P_{1} H}, \bar{U}_{P_{n} H}\right)$, maximum area for plants (MaxArea), and, given some conditions, the utility of other resources to plants $\left(U_{b P_{1}}, U_{b P_{n}}\right)$; 
- Obstructors: utility of other resources to humans $\left(U_{b H_{1}}, U_{b H_{n}}\right)$, and utility of other resources to plants $\left(U_{b P_{1}}, U_{b P_{n}}\right)$;

- Scalers: intrinsic growth rates $\left(r_{H}, r_{P}\right)$, utility per capita to the other population $\left(\bar{U}_{H_{1} P}, \bar{U}_{H_{n} P}, \bar{U}_{P_{1} H}, \bar{U}_{P_{n} H}\right)$, the utility of other resources $\left(U_{b H_{1}}, U_{b H_{n}}, U_{b P_{1}}\right.$, and $\left.U_{b P_{n}}\right)$, and the maximum area for plants (MaxArea).

Within the range of values explored, all parameters but the initial populations and the intrinsic growth rates $\left(r_{H}, r_{P}\right)$ displayed tipping points, i.e. threshold values beyond which the end-states of simulations change drastically (non-linear effect). The exact location of a tipping point in one parameter depends on the values of all others, indicating a generally strong interaction between their effects, and hence no single-cause explanation of a given end-state can be accurate.

Still, parameters vary significantly in importance when predicting the values of the coevolution coefficients at the end-state. We were able to rank the explanatory power of each parameter by fitting Random Forest Regression models where parameters are inputted as predictors in respect to each coevolution coefficient separately (Fig ??).

The same procedure was applied for the dependency coefficients and timings; see section 5.2 in [61]. The assessment of parameter importance for the dependency coefficients displayed a similar pattern, only highlighting those parameters with a direct impact on the carrying capacity of the respective population (greens and blues). While the intrinsic growth rates $\left(r_{H}, r_{P}\right)$ have the highest impact on the timing of coevolution, all other parameters are scored similarly, having at least some importance for one or both populations. Parameter explorations revealed that timing $_{H}$, timing $_{P}$ and $t_{\text {end }}$ are larger, the closer parameter values are to a tipping point. In those liminal cases, the coevolutionary process can take up to three times longer.

\section{Number of types, undirected variation and intrinsic growth rate}

The numbers of types in both human and plant populations $\left(n_{H}, n_{P}\right)$ facilitate change (i.e. facilitators). However, these two parameters stand out as the least important. Such a result is desirable given that the aspect regulated by these parameters - i.e. the discretionality of population variation - is a necessary artefact of the model and can only translate to arbitrary classifications when regarding real populations. Ultimately, 
every individual in a real population could be the single instance of their own type. The 377 overall low importance of these parameters warrants future explorations to treat these ${ }_{378}$ as constants, preferably setting them at values much greater than unity $\left(n_{A} \gg 1\right)$.

The levels of undirected variation $\left(v_{H}, v_{P}\right)$ are also facilitators. With higher variation, there are more individuals belonging to stronger mutualism types. Though unfit to the initial conditions, these are the pioneer individuals that may eventually build up the necessary selective pressure on the partner-population and trigger coevolution. The positive relationship between undirected variation and occurrence of coevolution agrees with Fisher's fundamental theorem of natural selection [65,66], according to which higher variance increases the rate of adaptation of a species; which, in this case, leads to stronger mutualism.

Intrinsic growth rates $\left(r_{H}, r_{P}\right)$ are scalers that condition how fast populations levels change. Generally, higher intrinsic growth rates return shorter periods of population growth and change of type distribution. However, because they also define how rapid is the feedback cycle regulating the mutualistic selective pressures, they show a mirrored pattern where the intrinsic growth rate of one population has its greatest impact on the timing of change of the other population.

\section{Utility-related parameters}

Overall, the most important parameters in the HPC model are those characterising the potential of the mutualistic interaction between humans and plants (Fig ??); i.e. the utility per capita of type $n$ individuals to the other population $\left(\bar{U}_{P_{n} H}, \bar{U}_{H_{n} P}\right.$, or mU.HnP, mU.PnH). Although the correspondent values for type 1 individuals $\left(\bar{U}_{P_{1} H}\right.$, $\bar{U}_{H_{1} P}$, or mU.H1P, mU.PnH) also play a significant role, coevolution is more often enabled by the utility given by the higher-end types in the mutualistic spectrum. The effect of these parameters is mirrored (greens in Fig ??): $\bar{U}_{P_{n} H}$ mostly affects change in the human population and $\bar{U}_{H_{n} P}$ does it in the plant population. However, the utility per capita of type $n$ plants $\left(\bar{U}_{P_{n} H}\right)$ weights considerably on both humans and plants.

All four parameters related to the utility exchange between humans and plants set a range of utility per capita of each population type that amounts to population totals. Whenever these totals overcome the totals given by the other resources, the fitness scores will favour stronger mutualism types and trajectories will shift towards a 
successful coevolution (Fig ??).

The parameters determining the utility given by other resources $\left(U_{b H_{1}}, U_{b H_{n}}, U_{b P_{1}}, \quad{ }^{409}\right.$ and $\left.U_{b P_{n}}\right)$ are obstructors. Overall, the parameters corresponding to the human population $\left(U_{b H_{1}}, U_{b H_{n}}\right)$ have a stronger effect than those related to plants (blues in

Fig ??). The two parameters regulating the utility of other resources to plants $\left(U_{b P_{1}}\right.$, $\left.U_{b P_{n}}\right)$ can also be facilitators depending on the conditions set by other parameters; however, their effect is the weakest of all eight parameters associated with utility (greens and blues in Fig ??).

The parameters associated with utility are also important scalers since they have a direct effect on carrying capacities. The parameters contributing to the carrying capacity for humans $\left(\bar{U}_{P_{1} H}, \bar{U}_{P_{n} H}, U_{b H_{1}}\right.$, and $\left.U_{b H_{n}}\right)$ are able to influence scale more freely because they are not capped by MaxArea. In particular, the utility of other resources to type 1 individuals $\left(U_{b P_{1}}, U_{b H_{1}}\right)$ can condition almost entirely the respective carrying capacity — and consequently the population levels - at the end state. These parameters alone can generate trajectories where the human population at the end-state varies from a few to thousands of individuals, without ever incurring in coevolution.

Trajectories with coevolution can be very different (compare Fig ??E to Fig ??) mainly due to the amount of space available for plants (MaxArea) and the conditions regulating the mutual utility between humans and plants $\left(\bar{U}_{H_{1} P}, \bar{U}_{H_{n} P}, \bar{U}_{P_{1} H}\right.$, and $\left.\bar{U}_{P_{n} H}\right)$. These are important facilitators, but also have the potential for producing end-states that differ dramatically in the sheer size of the human and plant populations $(H, P)$. For instance, an overall low utility of plant types to humans $\left(\bar{U}_{P_{1} H}, \bar{U}_{P_{n} H}\right)$ can still produce end-states with coevolution that are indistinguishable in terms of human population size from others without coevolution, where the overall utility of other resources to humans is sufficiently high.

Surprisingly, full-fledged coevolution can still happen when type $n$ individuals contribute less than type 1 individuals (e.g., $\bar{U}_{P_{n} H}<\bar{U}_{P_{1} H}$ ). For instance, when $\bar{U}_{P_{n} H}=1.5$ and $\bar{U}_{P_{1} H}=3$ in Fig ??. This happens whenever the population total (e.g., $U_{P H}$ ) overcomes the amount given by other resources (e.g., $\left.U_{b H}\right)$. This discovery indicates that, at least under the assumptions of this model, the adaptation to mutualism could cause the deterioration of the contribution of individual organisms while still increasing population numbers. 


\section{Discussion}

Much of the groundwork that helped understand the evolutionary dynamics of plant domestication comes from archaeology, and more specifically from archaeobotany.

Harris [67] theorised the process of domestication as composed of three stages: 1) wild

food procurement by hunting and gathering societies; 2) cultivation of wild plants; and

the 3) domestication syndrome fixation that established true agriculture of domestic

plants. The early datasets, mostly coming from the Fertile Crescent, were interpreted as suggesting a 'rapid transition' between these stages due to a strong and direct human selection favouring interesting characters, such as non-brittle spikelets in cereals [68] and suppression of seed dormancy in legumes [69]. However, the current archaeological record suggests that such transitions could involve a period of pre-domestication cultivation lasting thousands of years [70,71], followed by fixation of the emerging domestic traits, again over thousands of years; see e.g. for cereals [72]. This process, leading to the evolution of domesticated and commensal species, seems to have been a response to the emergence of human-modified environments from the end of the last glaciation [73]. Both the domesticated plants and human species benefited from this co-evolutionary process, leading to stronger mutualism [49].

\section{Multiple factors, multiple scenarios}

The HPC model illustrates the multiplicity of the dynamics embedded within ecological and socio-economic shifts such as the neolithisation. The exploration of the model reinforces the premise that, to explain the domestication of plants and the adoption of agricultural practices, we must assume that single-factor explanations do not fit this multiple reality $[1,5]$. The great variety of scenarios regarding the characteristics of crops and the ecological milieus, as well as the different social, cultural and technological settings in humans, highlights the complexity of the process and the inevitability of generating case-specific narratives when interpreting the evidence. However, the HPC model goes beyond the replication of single-case idiosyncrasies and contains the formalisation of a general mechanism: the coevolution of humans and plants. This model is able to generate a wide diversity of simulated trajectories and end-states, which can be then used to produce explanatory frameworks for specific 
real-world cases. Therefore, the HPC model does not aim to reproduce historical processes per se but different possible scenarios, some of which might be identified through specific lines of evidence.

The model points to several aspects that can explain the emergence of agricultural systems. Some of these aspects, like the utility per capita to the other population, have been already part of the archaeological and botanical discourse, albeit not as a formal model [68]. Furthermore, the model shows that a small increase or decrease around a threshold value can produce major changes in the system (tipping point) and that, for coevolution to occur, all parameters showing tipping points must be either beyond or below a particular threshold, which, in turn, depends on the values of all other parameters.

The HPC model also shows that certain differences between human and plant populations can have an important effect on the outcome of human-plant coevolution. The selective pressure of one versus the other may vary significantly among parameter settings, thus producing qualitatively different scenarios.

At one end of the mutualism spectrum, the model can generate scenarios where the subsistence relies heavily on the plant population and the selective pressure is sufficient to drive a substantial change on plant type frequency and population levels, thus leading to some form of agricultural system. At the other end, the model produces outcomes where there is low human-on-plant pressure and humans have many (and preferred) alternative food sources. In such instances, wild plant forms are maintained in the population and low densities are retained. Human subsistence in such cases relies mostly upon other resources, which might still allow for high population densities independently of the plant population; e.g., fishing and complex hunter-gatherers $[74,75]$. Between these extreme end-state scenarios, the model also simulates other "realities" in which only one population exerts enough selective pressure over the other for it to shift towards stronger mutualism types: societies cultivating plants that, though affected, remain not fully domesticated (cultivation without domestication), or those foraging plant populations that increase their productivity without humans investing more time in them (domestication without cultivation). 


\section{Intensification and the coevolutionary dynamics of prehistoric plant management}

In most early cases, the adoption of agriculture seems to be the culmination of a long process with deep roots in hunter-gatherer societies [76]. Archaeological literature traditionally considers this process to be fuelled by a series of changes related to food resource diversification [77, 78] and, particularly for plants, intensification [79-82]. Within this context of change, intensive gathering and cultivation have been considered economic practices within a continuum, where some plant species are gathered opportunistically and others systematically exploited. At the beginning of every transition to agriculture, predatory strategies (fishing, hunting, and gathering) were central to human subsistence, while mutualism (plant tending and animal husbandry), if any, were complementary [30].

The theoretical continuum between resource management, domestication, and agriculture assumes that the existence of each foregoer component is paramount for the development of the next "step". However, any one of these phenomena does not inevitably lead to the next [4]. Assuming that in some cases there is an effective transition to agriculture, the focus shifts from a wide range of prey-like resources to a relatively small number of very successful mutualism partners, among which domesticated plants eventually become the basic source of staple food. In this framework, the coevolution between humans and plants can be defined as a process mediating between weaker and stronger mutualism which can involve many stages, each with a qualitative change in the distribution of types and consecutive boom and stabilisation of both populations.

The HPC model allows identifying various regimes of mutualism between humans and plants. The model, in fact, represents a wide range of scenarios which, from the human point of view, consist of different combinations of wild/domesticated plant food resources and modes of exploitation of these, with variable commitments in terms of diet and investment. These strategies can be interpreted as mixed economies, which have been shown to be possible, viable, and even resilient socio-economic choices.

Within the specialized literature, mixed economies are usually understood as minor or marginal socio-economic systems, defined either as the combination of different 
strategies of low-level food production [83] or as by-products of a transitory, thus not stable, stage [84].

These strategies are not necessarily implemented as static combinations, but also as seasonal or periodical sets, shifting from one strategy to another $[85,86]$. In addition, they might not be a clear rational decision adopted by specific social agents or groups in charge of the economic activities, but a reality formed by the aggregation of multiple decision-making processes at the community level, throughout generations.

There is a strong relationship between richness of viable economical options and the specialisation and diversification in subsistence strategies [87-90]. Specialisation and diversification are thought to have first occurred during the Mesolithic for intensifying the acquisition of resources and are considered a preamble for the implementation of agricultural practices [91]. Although the idea of intensification might seem to be nourishing the continuum concept, there is a strong debate about the reasons and conditions under which intensification takes place in hunter-gatherer societies [92].

With this work, we aim to show how the succession of mixed economies are intrinsic parts of the coevolutionary dynamics between human and plants, and illuminate why these culminated, in many cases, in the emergence of agriculture.

\section{Insights on the Neolithic Demographic Transition}

In archaeological theory, the origins of agriculture is often defined as the birth of a new socioeconomic paradigm that involved important changes in human demography and social organization, such as increased hierarchy and division of labour. Among these changes, the most striking is the unprecedented population growth that usually followed the adoption of agriculture, i.e. the Neolithic Demographic Transition [93-95].

The HPC model considers the relationship between plant utility and human needs (population pressure) but also the positive effects humans can have on plant growth. The latter involves a delayed improvement of plant utility to humans, through the evolution of traits and sheer population growth, and an increasing human population growth, putting pressure on old and new food resources. Low population pressure, given by either low population density or abundance of food resources, has been argued as a precondition for increasing growth rates in human populations [86]. The demographic 
increase by the end of the Upper Palaeolithic shown by the archaeological record has been considered as a possible cause of a series of intensification processes (such as the intensification of plant gathering or the expansion of coastal populations and an increase in the consumption of coastal and marine resources). At the same time, either the intensification of resource exploitation and/or the adoption of agricultural practices (both increasing the productivity per area but also involving labour-intensive, time-sensitive activities) might have fostered the abandonment of a series of measures controlling fertility, resulting in a population increase.

A few studies have recently focused on the various demographic booms and busts identified during the Early Neolithic in Europe [16] and which may be interpreted as the possible diverse outcomes of the neolithisation process. While neolithisation intuitively implies a population boom due to the overall increase in food availability, not all the instances of shifting to an agricultural economy appear to have been demographically successful. The HPC model suggests a possible explanation for population busts within its formal framework: a momentary decrease in the adaptive fitness of the population and, thus, of the carrying capacity of the environment.

The growth of the human population may have a series of implications. First, a higher demand on the available resources that become manifest in the selective pressure on the plant population or other available resources (mixed economy). This may have positively affected the domestication process, by increasing plant bulk productivity, but also produced a series of changes fostering the hunter-gatherer strategy to be less effective when combined with a more invested plant cultivation. When cultivation becomes a priority, there is an expectation for societies or groups within societies to become more sedentary, at least seasonally, so that crops are properly monitored during growth. As a consequence, there would be a reduction in the fitness of the hunter-gatherer strategies. Firstly, because some expertise may be lost, even within a generation, as a considerable part of the labour and efforts for cultural transmission would be focused on cultivation. Secondly, with sedentism (or partial sedentism), the catchment area available for foraging would quickly be impoverished, having less time to recover and at the same time suffering the effects of expanding cultivation practices. Thirdly, the human population will be pressured to adapt to the needs and schedule of the cultivated plant species, which might be incompatible with the ones required for 
gathering or hunting specific wild resources.

\section{Conclusions}

Considering the potential of the results above, we highlight the simple and conservative nature of the HPC model. All the diversity observed in terms of both attractors and trajectories was generated by the combination of only two submodels, the Verhulst-Pearl models in theoretical biology. The sole fact that a relatively simple model can greatly help understand complex phenomena, such as the origin of agriculture, argues for the use of formal models and specifically simulation approaches in archaeology.

The HPC model also demonstrate that population-level (top-down) theory can still produce useful insights. Strong explanatory frameworks can be achieved without the fine insights of case-wise detail; an approach often resisted by archaeologists, but which is fully accepted whenever data is interpreted. In this sense, we consider that formal models are fundamental tools to present, demonstrate and explore any theoretical proposal. The HPC model offers a solid basis for the development of generative (bottom-up) models [96-98], and is complementary to approaches focusing on plant domestication syndrome through phenotypic and genetic characterisation $[99,100]$.

According to the HPC model, there are several factors involved in the facilitation or obstruction of emerging agricultural systems. Although it confirms the expectation of attributing several causes to the origin of agriculture, the model further explains how multiple factors could be compatible with asserting causation in a historical sense (i.e., concatenation of events).

In the HPC model, the state of the system connecting humans and the plant species is sensitive to almost the totality of the thirteen parameters. More precisely, this sensitivity is expressed as a rather abrupt shift (tipping point) from a weak to a strong mutualistic state, or vice-versa, depending on the threshold values for each parameter, which are in turn dependent on the current values of every other parameter. Then, according to our model, the emergence of agriculture could be explained by the confluence of all these conditions at specific times and places. However, it seems unlikely that, for the same case of emergence, all these conditions change and cross 
multiple thresholds simultaneously. Conversely, still within the HPC model, we may

envisage scenarios in specific regions at specific moments (i.e. under a specific set of

other conditions) where few or even single conditions changed and triggered the

emergence of agriculture. In this case, certain factors may be considered the cause of

the phenomenon in a more deterministic sense.

Complementing the identification of factors that play a role in the human-plant coevolutionary dynamics, the HPC model further allows assessing the differences in scale and timing between case trajectories. This capability seems to be especially relevant to understand the many cases of non-industrial agricultural systems documented by archaeology and ethnography. By controlling parameter on a case-by-case basis, further work with the HPC model would yield insight on the reliability of particular hypotheses of how agricultural systems emerged in the past, and help explain why some origins are more observable than others.

\section{Acknowledgments}

This research is part of the activities of the Culture and Socioecological Dynamics Research Group (CaSEs), a Quality Group of the Generalitat de Catalunya (2017 SGR212) (JAM, MM, DZ), and was supported by the CULM project

(HAR2016-77672-P), funded by the former Spanish Ministry of Economy and Competitiveness (MINECO) (DZ), and the TwoRains project, funded by the European Research Council (ERC) under the European Union's Horizon 2020 research and innovation programme (grant agreement no 648609) (AA). Previous development was also made possible through the support of the SimulPast Project - Consolider Ingenio 2010 (CSD2010-00034), funded by the former Spanish Ministry for Science and Innovation (MICIN) (AA, JAM, MM, DZ), and the CAMOTECCER project (HAR2012-32653) and FPI contract (BES-2013-062691), funded by MINECO (AA).

Figure 2 contains modified versions of the Plant icon release by Bakunetsu Kaito under CC-BY 3.0 (available at: https://thenounproject.com/icon/961532/) and the People icon released by Fahmihorizon under CC-BY 3.0 (https://thenounproject.com/icon/1426355/). 


\section{References}

1. Aiello LC. The Origins of Agriculture: New Data, New Ideas. Current Anthropology. 2011;52(S4):S161-S162. doi:10.1086/660154.

2. Price TD, Bar-Yosef O. The origins of agriculture: New data, new ideas; 2011. Available from: https://doi.org/10.1086/659964.

3. Larson G, Piperno DR, Allaby RG, Purugganan MD, Andersson L, Arroyo-Kalin M, et al.. Current perspectives and the future of domestication studies; 2014. Available from: www.pnas.org/cgi/doi/10.1073/pnas.1323964111.

4. Zeder MA. Core questions in domestication research. Proceedings of the National Academy of Sciences of the United States of America.

2015;112(11):3191-3198. doi:10.1073/pnas.1501711112.

5. Fuller DQ, Denham T, Arroyo-Kalin M, Lucas L, Stevens CJ, Qin L, et al. Convergent evolution and parallelism in plant domestication revealed by an expanding archaeological record. Proceedings of the National Academy of Sciences of the United States of America. 2014;111(17):6147-6152. doi:10.1073/pnas.1308937110.

6. Gremillion KJ, Barton L, Piperno DR. Particularism and the retreat from theory in the archaeology of agricultural origins. Proceedings of the National Academy of Sciences of the United States of America. 2014;111(17):6171-6177. doi:10.1073/pnas.1308938110.

7. Piperno DR. A model of agricultural origins. Nature Human Behaviour. 2018;2(7):446-447. doi:10.1038/s41562-018-0390-8.

8. Piperno DR. The origins of plant cultivation and domestication in the New World Tropics patterns, process, and new developments. Current Anthropology. 2011;52(SUPPL. 4). doi:10.1086/659998.

9. Richerson PJ, Boyd R, Bettinger RL. Was Agriculture Impossible during the Pleistocene but Mandatory during the Holocene? A Climate Change Hypothesis. American Antiquity. 2001;66(03):387-411. doi:10.2307/2694241. 
10. Bar-Yosef O. Climatic fluctuations and early farming in west and East Asia; 2011.

11. Wright Jr HE. Environmental Determinism in Near Eastern Prehistory. Current Anthropology. 1993;34(4):458-469. doi:10.1086/204193.

12. Cauvin J. The birth of the Gods and the origins of agriculture. Cambridge University Press; 2000.

13. Cauvin J, Hodder I, Rollefson GO, Bar-Yosef O, Watkins T. Review of The Birth of the Gods and the Origins of Agriculture by Jacques Cauvin, Translated by Trevor Watkins (New Studies in Archaeology). Cambridge Archaeological Journal. 2001;11(1):105-121. doi:10.1017/S0959774301000063.

14. Abbo S, Gopher A. Near Eastern Plant Domestication: A History of Thought. Trends in Plant Science. 2017;22(6):491-511. doi:10.1016/j.tplants.2017.03.010.

15. Belfer-Cohen A, Nigel Goring-Morris A. Becoming farmers: The inside story. Current Anthropology. 2011;52(SUPPL. 4). doi:10.1086/658861.

16. Shennan S, Downey SS, Timpson A, Edinborough K, Colledge S, Kerig T, et al. Regional population collapse followed initial agriculture booms in mid-Holocene Europe. Nature Communications. 2013;4(1):1-8. doi:10.1038/ncomms3486.

17. Childe VG. Man makes himself. London: Watts and Co; 1936.

18. Asouti E, Fuller DQ. A Contextual Approach to the Emergence of Agriculture in Southwest Asia. Current Anthropology. 2013;54(3):299-345. doi:10.1086/670679.

19. Denham T, Haberle S, Lentfer C. New evidence and revised interpretations of early agriculture in Highland New Guinea. Antiquity. 2004;78(302):839-857. doi:10.1017/S0003598X00113481.

20. Erickson CL. Intensification, political economy, and the farming community; Defense of a bottom-up perspective of the past. In: Marcusand J, Stanish C, editors. Agricultural Strategies. Los Angeles: Cotsen Institute of Archaeology, University Of California; 2006. p. 233-265. Available from: http://repository. upenn. edu/anthro\{_\}papers/5. 
21. Gage TB, DeWitte S. What do we know about the agricultural demographic transition? Current Anthropology. 2009;50(5):649-655. doi:10.1086/605017.

22. McCorriston J. Acorn eating and agricultural origins: California ethnographies as analogies for the ancient Near East. Antiquity. 1994;68(258):97-107. doi:10.1017/S0003598X00046238.

23. Roscoe PB. On the 'Pacification' of the European Neolithic: Ethnographic analogy and the neglect of history. World Archaeology. 2009;41(4):578-588. doi:10.1080/00438240903345621.

24. Allaby RG, Brown TA, Fuller DQ. A simulation of the effect of inbreeding on crop domestication genetics with comments on the integration of archaeobotany and genetics: a reply to Honne and Heun. Vegetation History and Archaeobotany. 2010;19(2):151-158. doi:10.1007/s00334-009-0232-8.

25. Piperno DR. Assessing elements of an extended evolutionary synthesis for plant domestication and agricultural origin research. Proceedings of the National Academy of Sciences. 2017;114(25):6429-6437. doi:10.1073/pnas.1703658114/-/DCSupplemental.

26. Fuller D, Lucas L, Gonzalez Carretero L, Stevens C. From intermediate economies to agriculture: trends in wild food use, domestication and cultivation among early villages in southwest Asia. Paleorient. 2018;44(2):61-76.

27. Allaby RG, Stevens CJ, Kistler L, Fuller DQ. 8. In: Genetic Revelations of a New Paradigm of Plant Domestication as a Landscape Level Process. John Wiley \& Sons, Ltd; 2021. p. 321-343. Available from: https://onlinelibrary.wiley.com/doi/abs/10.1002/9781119828235.ch8.

28. Abbo S, Gopher A. Plant domestication in the Neolithic Near East: The humans-plants liaison. Quaternary Science Reviews. 2020;242:106412. doi:10.1016/j.quascirev.2020.106412.

29. Heun M, Abbo S, Lev-Yadun S, Gopher A. A critical review of the protracted domestication model for Near-Eastern founder crops: linear regression, 
long-distance gene flow, archaeological, and archaeobotanical evidence. Journal of Experimental Botany. 2012;63(12):4333-4341. doi:10.1093/jxb/ers162.

30. Ahedo V, Zurro D, Caro J, Galán JM. Let's go fishing: A quantitative analysis of subsistence choices with a special focus on mixed economies among small-scale societies. PLOS ONE. 2021;16(8):e0254539.

doi:10.1371/JOURNAL.PONE.0254539.

31. Piperno DR, Ranere AJ, Dickau R, Aceituno F. Niche construction and optimal foraging theory in Neotropical agricultural origins: A re-evaluation in consideration of the empirical evidence. Journal of Archaeological Science.

2017;78:214-220. doi:10.1016/j.jas.2017.01.001.

32. Smith BD. Niche construction and the behavioral context of plant and animal domestication. Evolutionary Anthropology. 2007;16(5):188-199.

doi:10.1002/evan.20135.

33. Rowley-Conwy P, Layton R. Foraging and farming as niche construction: Stable and unstable adaptations. Philosophical Transactions of the Royal Society B: Biological Sciences. 2011;366(1566):849-862. doi:10.1098/rstb.2010.0307.

34. Laland K, Odling-Smee J, Endler J. Niche construction, sources of selection and trait coevolution. Interface Focus. 2017;7(5):20160147.

doi:10.1098/rsfs.2016.0147.

35. Stiner MC, Kuhn SL. Are we missing the "sweet spot" between optimality theory and niche construction theory in archaeology? Journal of Anthropological Archaeology. 2016;44:177-184. doi:10.1016/J.JAA.2016.07.006.

36. Laland KN, O'Brien MJ. Niche Construction Theory and Archaeology. Journal of Archaeological Method and Theory. 2010;17(4):303-322. doi:10.1007/s10816-010-9096-6.

37. Wallach E. Niche construction theory as an explanatory framework for human phenomena. Synthese. 2016;193:2595-2618. doi:10.1007/s11229-015-0868-0. 
38. Brown TA. The Role of Humans in a Protracted Transition From Hunting-Gathering to Plant Domestication in the Fertile Crescent. Frontiers in Plant Science. 2018;9:1287. doi:10.3389/fpls.2018.01287.

39. Gerbault P, Allaby RG, Boivin N, Rudzinski A, Grimaldi IM, Pires JC, et al. Storytelling and story testing in domestication. Proceedings of the National Academy of Sciences of the United States of America. 2014;111(17):6159-6164. doi:10.1073/pnas.1400425111.

40. Allaby RG, Fuller DQ, Brown TA. The genetic expectations of a protracted model for the origins of domesticated crops. Proceedings of the National Academy of Sciences of the United States of America. 2008;105(37):13982-6. doi:10.1073/pnas.0803780105.

41. Isern N, Fort J, Carvalho AF, Gibaja JF, Ibañez JJ. The Neolithic Transition in the Iberian Peninsula: Data Analysis and Modeling. Journal of Archaeological Method and Theory. 2014;21(2):447-460. doi:10.1007/s10816-013-9193-4.

42. Jerardino A, Fort J, Isern N, Rondelli B. Cultural Diffusion Was the Main Driving Mechanism of the Neolithic Transition in Southern Africa. PLoS ONE. 2014;9(12):e113672. doi:10.1371/journal.pone.0113672.

43. Fort J. Demic and cultural diffusion propagated the Neolithic transition across different regions of Europe. Journal of The Royal Society Interface. 2015;12(106):20150166. doi:10.1098/rsif.2015.0166.

44. Lemmen C, Gronenborn D, Wirtz KW. A simulation of the Neolithic transition in Western Eurasia. Journal of Archaeological Science. 2011;38(12):3459-3470. doi:10.1016/J.JAS.2011.08.008.

45. Freeman J, Anderies JM. Intensification, Tipping Points, and Social Change in a Coupled Forager-Resource System. Human Nature. 2012;23(4):419-446. doi:10.1007/s12110-012-9154-8.

46. Freeman J, Peeples MA, Anderies JM. Toward a theory of non-linear transitions from foraging to farming. Journal of Anthropological Archaeology.

2015;40:109-122. doi:10.1016/j.jaa.2015.07.001. 
47. Brock WA, O'Brien MJ, Bentley RA. Validating niche-construction theory through path analysis. Archaeological and Anthropological Sciences.

2016;8(4):819-837. doi:10.1007/s12520-015-0257-0.

48. Janzen D. When is it Coevolution? Evolution. 1980;34(May):611-612.

49. Rindos D. The Origins of Agriculture: An evolutionary Perspective. London: Academic Press; 1984.

50. Purugganan MD. Evolutionary Insights into the Nature of Plant Domestication. Current Biology. 2019;29(14):R705-R714. doi:10.1016/j.cub.2019.05.053.

51. Durham WH. Coevolution: Genes, Culture, and Human Diversity. Stanford University Press; 1991.

52. Graham K. Fungal-Insect Mutualism in Trees and Timber. Annual Review of Entomology. 1967;12(1):105-126. doi:10.1146/annurev.en.12.010167.000541.

53. Janzen DH. Coevolution of Mutualism between Ants and Acacias in Central America. Evolution. 1966;20(3):249-275.

doi:10.1111/j.1558-5646.1966.tb03364.x.

54. R Core Team. R: A language and environment for statistical computing; 2019. Available from: https://www.r-project.org/.

55. Schuster P, Sigmund K. Replicator Dynamics. Journal of Theoretical Biology. 1983;100(3):533-538. doi:10.1016/0022-5193(83)90445-9.

56. Kingsland S. The Refractory Model: The Logistic Curve and the History of Population Ecology. The Quarterly Review of Biology. 1982;57(1):29-52. doi:10.1086/412574.

57. Pianka ER. Evolutionary Ecology. New York: Harper and Row; 1974.

58. Harper M. The Replicator Equation as an Inference Dynamic. arXiv preprint. $2009 ;.$

59. McKay MD, Beckman RJ, Conover WJ. A Comparison of Three Methods for Selecting Values of Input Variables in the Analysis of Output from a Computer Code. Technometrics. 1979;21(2):239-245. doi:10.2307/1268522. 
60. Damblin G, Couplet M, Iooss B. Numerical studies of space-filling designs: Optimization of Latin Hypercube Samples and subprojection properties. Journal of Simulation. 2013;7(4):276-289. doi:10.1057/jos.2013.16.

61. Angourakis A, Alcaina-Mateos J. Andros-Spica/hpcModel: Human-Plant Coevolution model: source files, simulation interface, sensitivity analysis report and documentation. Zenodo. 2020;doi:10.5281/zenodo.3881915.

62. Liaw A, Wiener M. Classification and Regression by randomForest. R News. $2002 ; 2(3): 18-22$.

63. Pereda M, Zurro D, Santos JI, Briz i Godino I, Álvarez M, Caro J, et al. Emergence and Evolution of Cooperation Under Resource Pressure. Scientific Reports. 2017;7(1):45574. doi:10.1038/srep45574.

64. Kohavi R. A Study of Cross-Validation and Bootstrap for Accuracy Estimation and Model Selection. International Joint Conference of Artificial Intelligence. $1995 ;.$

65. Fisher RA. The Genetical Theory Of Natural Selection. Oxford: Claredon Press; 1930. Available from:

https://archive.org/details/geneticaltheoryo031631mbp/page/n12.

66. Frank SA, Slatkin M. Fisher's fundamental theorem of natural selection. Trends in Ecology and Evolution. 1992;7(3):92-95. doi:10.1016/0169-5347(92)90248-A.

67. Harris DR. An evolutionary continuum of people-plant interaction. In: Harris DR, Hillman GC, editors. Foraging and Farming: The evolution of Plant Exploitation. London: Unwin Hyman; 1989. p. 11-26.

68. Abbo S, Lev-Yadun S, Gopher A. Plant Domestication and Crop Evolution in the Near East: On Events and Processes. Critical Reviews in Plant Sciences. 2012;31(3):241-257. doi:10.1080/07352689.2011.645428.

69. Blumler MA. Modelling the origins of legume domestication and cultivation. Economic Botany. 1991;45(2):243-250. doi:10.1007/BF02862051. 
70. Weiss E, Kislev ME, Hartmann A. Autonomous cultivation before domestication. Science. 2006;312(5780):1608-1610. doi:10.1126/science.1127235.

71. Willcox G, Stordeur D. Large-scale cereal processing before domestication during the tenth millennium cal BC in northern Syria. Antiquity. 2012;86(331):99-114. doi:10.1017/S0003598X00062487.

72. Tanno KiKI, Willcox G. How fast was wild wheat domesticated? Science. 2006;311(5769):1886. doi:10.1126/science.1124635.

73. Allaby RG, Kistler L, Gutaker RM, Ware R, Kitchen JL, Smith O, et al. Archaeogenomic insights into the adaptation of plants to the human environment: Pushing plant-hominin co-evolution back to the Pliocene. Journal of Human Evolution. 2015;79:150-157. doi:10.1016/j.jhevol.2014.10.014.

74. Ames KM. The Northwest Coast. Evolutionary Anthropology. 2003;12(1):19-33. doi:10.1002/evan.10102.

75. Bailey G, Milner N. Coastal hunter-gatherers and social evolution. Before Farming. 2002;2002(3-4):1-22. doi:10.3828/bfarm.2002.3-4.1.

76. Revedin A, Aranguren B, Becattini R, Longo L, Marconi E, Lippi MM, et al. Thirty thousand-year-old evidence of plant food processing. Proceedings of the National Academy of Sciences of the United States of America. 2010;107(44):18815-18819. doi:10.1073/pnas.1006993107.

77. Kotzamani G, Livarda A. People and plant entanglements at the dawn of agricultural practice in Greece. An analysis of the Mesolithic and early Neolithic archaeobotanical remains. Quaternary International. 2018;496:80-101. doi:10.1016/j.quaint.2018.04.044.

78. Arranz-Otaegui A, González Carretero L, Roe J, Richter T. "Founder crops" v. wild plants: Assessing the plant-based diet of the last hunter-gatherers in southwest Asia. Quaternary Science Reviews. 2018;186:263-283. doi:10.1016/j.quascirev.2018.02.011. 
79. Lourandos H, Ross A. The Great 'Intensification Debate': Its History And Place In Australian Archaeology. Australian Archaeology. 1994;39(1):54-63. doi:10.1080/03122417.1994.11681528.

80. Morrison KD. The intensification of production: Archaeological approaches. Journal of Archaeological Method and Theory. 1994;1(2):111-159. doi:10.1007/BF02231414.

81. Zvelebil M. Plant Use in the Mesolithic and its Role in the Transition to Farming. Proceedings of the Prehistoric Society. 1994;60(1):35-74. doi:10.1017/S0079497X00003388.

82. Morgan C. Is it Intensification Yet? Current Archaeological Perspectives on the Evolution of Hunter-Gatherer Economies. Journal of Archaeological Research. 2015;23(2):163-213. doi:10.1007/s10814-014-9079-3.

83. Smith BD. Documenting plant domestication: The consilience of biological and archaeological approaches; 2001. Available from: http: //www.pnas.org/cgi/doi/10.1073/pnas.98.4.1324.

84. Keegan WF. The Optimal Foraging Analysis of Horticultural Production. American Anthropologist. 1986;88(1):92-107. doi:10.1525/aa.1986.88.1.02a00060.

85. Downey SS, Haas WR, Shennan SJ. European Neolithic societies showed early warning signals of population collapse. Proceedings of the National Academy of Sciences of the United States of America. 2016;113(35):9751-9756. doi:10.1073/pnas.1602504113.

86. Svizzero S. Foraging Wild Resources: Evolving Goals of an Ubiquitous Human Behavior. Anthropology News. 2016;04(01). doi:10.4172/2332-0915.1000161.

87. Vaquer J, Geddes D, Barbaza M, Erroux J. Mesolithic Plant Exploitation At the Balma Abeurador (France). Oxford Journal of Archaeology. 1986;5(1):1-18. doi:10.1111/j.1468-0092.1986.tb00127.x.

88. Stiner MC, Munro ND, Surovell TA. The tortoise and the hare. Current Anthropology. 2000;41(1):39-73. doi:10.1086/300102. 
89. Stiner MC. Thirty years on the "Broad Spectrum Revolution" and paleolithic demography. Proceedings of the National Academy of Sciences of the United States of America. 2001;98(13):6993-6996. doi:10.1073/pnas.121176198.

90. Zeder MA. The Broad Spectrum Revolution at 40: Resource diversity, intensification, and an alternative to optimal foraging explanations; 2012. Available from: https://doi.org/10.1016/j.jaa.2012.03.003.

91. Liu L, Bestel S, Shi J, Song Y, Chen X. Paleolithic human exploitation of plant foods during the last glacial maximum in North China. Proceedings of the National Academy of Sciences of the United States of America.

2013;110(14):5380-5385. doi:10.1073/pnas.1217864110.

92. Holly DH. The Place of "Others" in Hunter-Gatherer Intensification. American Anthropologist. 2005;107(2):207-220. doi:10.1525/aa.2005.107.2.207.

93. Bocquet-Appel JP, Bar-Yosef O. The Neolithic Demographic Transition and its Consequences. Springer Netherlands; 2008. Available from: http://link. springer.com/10.1007/978-1-4020-8539-0.

94. Gignoux CR, Henn BM, Mountain JL. Rapid, global demographic expansions after the origins of agriculture. Proceedings of the National Academy of Sciences of the United States of America. 2011;108(15):6044-6049. doi:10.1073/pnas.0914274108.

95. Goldberg A, Mychajliw AM, Hadly EA. Post-invasion demography of prehistoric humans in South America. Nature. 2016;532(7598):232-235. doi:10.1038/nature17176.

96. Epstein JM. Generative social science: studies in agent-based modeling. Princeton: Princeton University Press; 2006.

97. Cotto O, Schmid M, Guillaume F. Nemo-age: Spatially explicit simulations of eco-evolutionary dynamics in stage-structured populations under changing environments. Methods in Ecology and Evolution. 2020;11(10):1227-1236. doi:10.1111/2041-210X.13460. 
98. Zhang B, Deangelis DL. An overview of agent-based models in plant biology and ecology. Annals of Botany. 2020;126:539-557. doi:10.1093/aob/mcaa043.

99. Milla RN, Osborne CP, Turcotte MM, Violle C. Plant domestication through an ecological lens. Trends in Ecology \& Evolution. 2015;30(8):463-469. doi:10.1016/j.tree.2015.06.006.

100. Denham T, Barton H, Castillo C, Crowther A, Dotte-Sarout E, Florin SA, et al. The domestication syndrome in vegetatively-propagated field crops. Annals of Botany. 2020;125:581-597. doi:10.1093/aob/mcz212. 
bioRxiv preprint doi: https://doi.org/10.1101/2021.11.19.469342; this version posted November 19, 2021. The copyright holder for this preprint

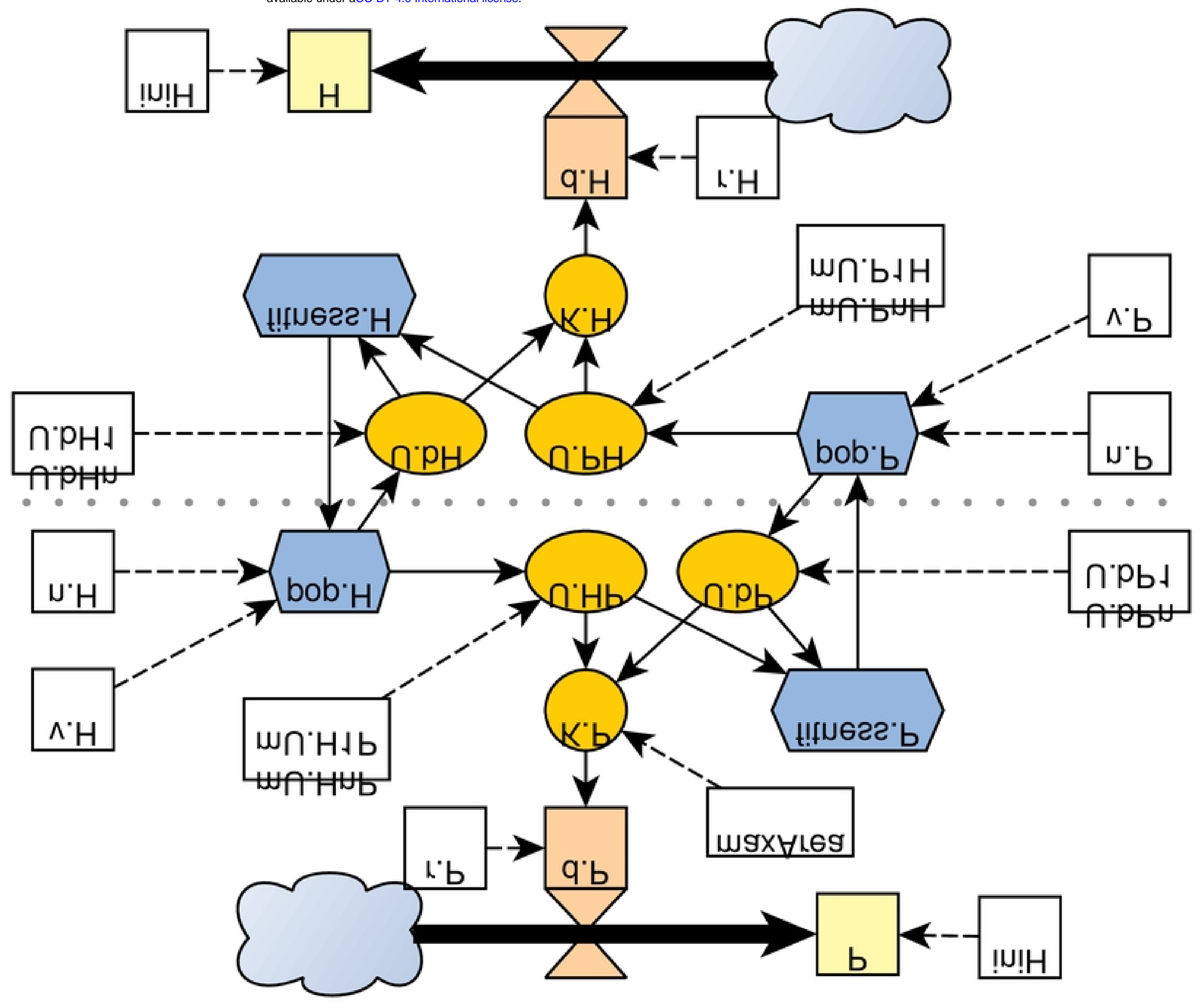

Figure 


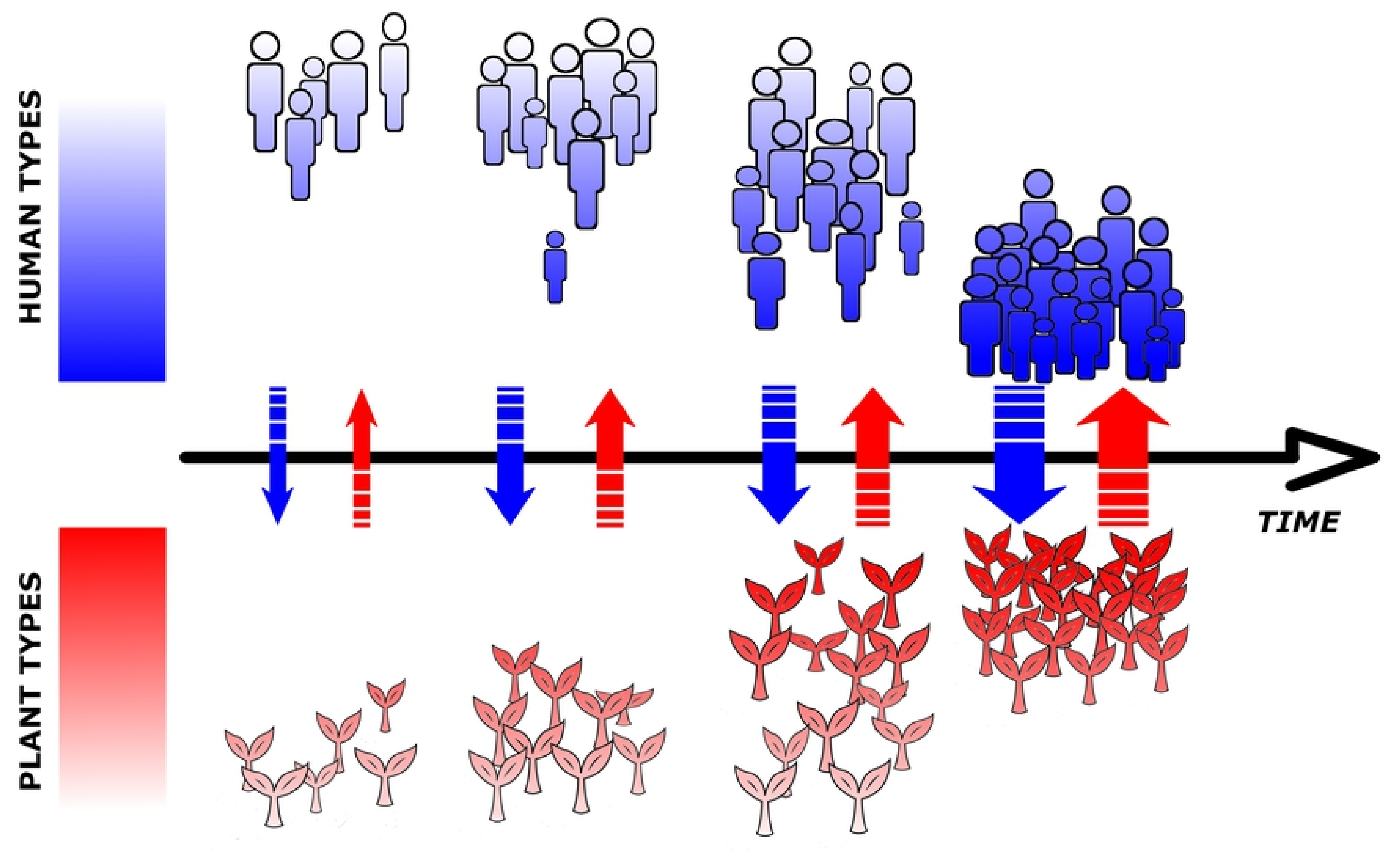

Figure 


\section{A}

B

C

D

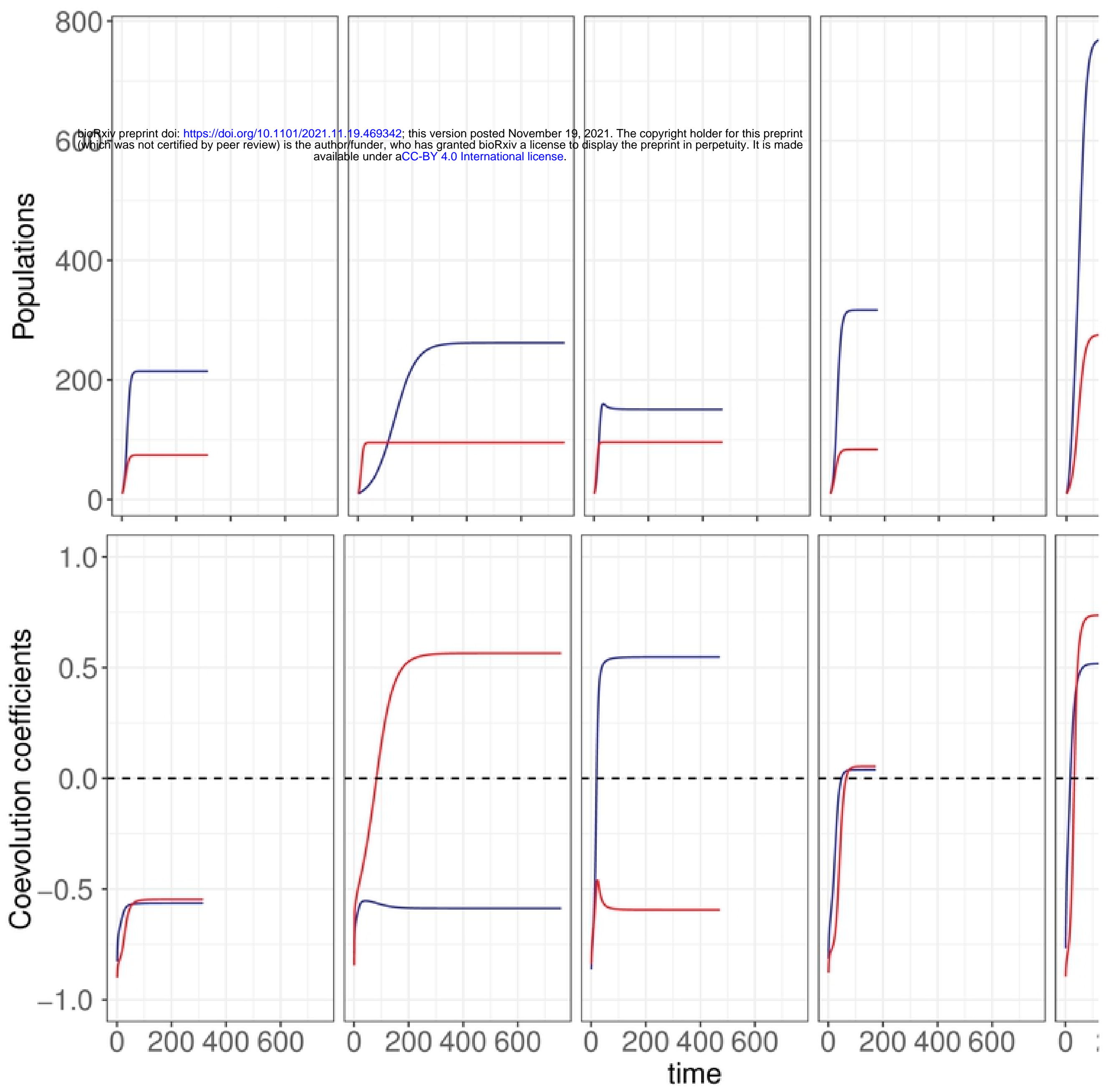

- Humans - Plants

Figure 

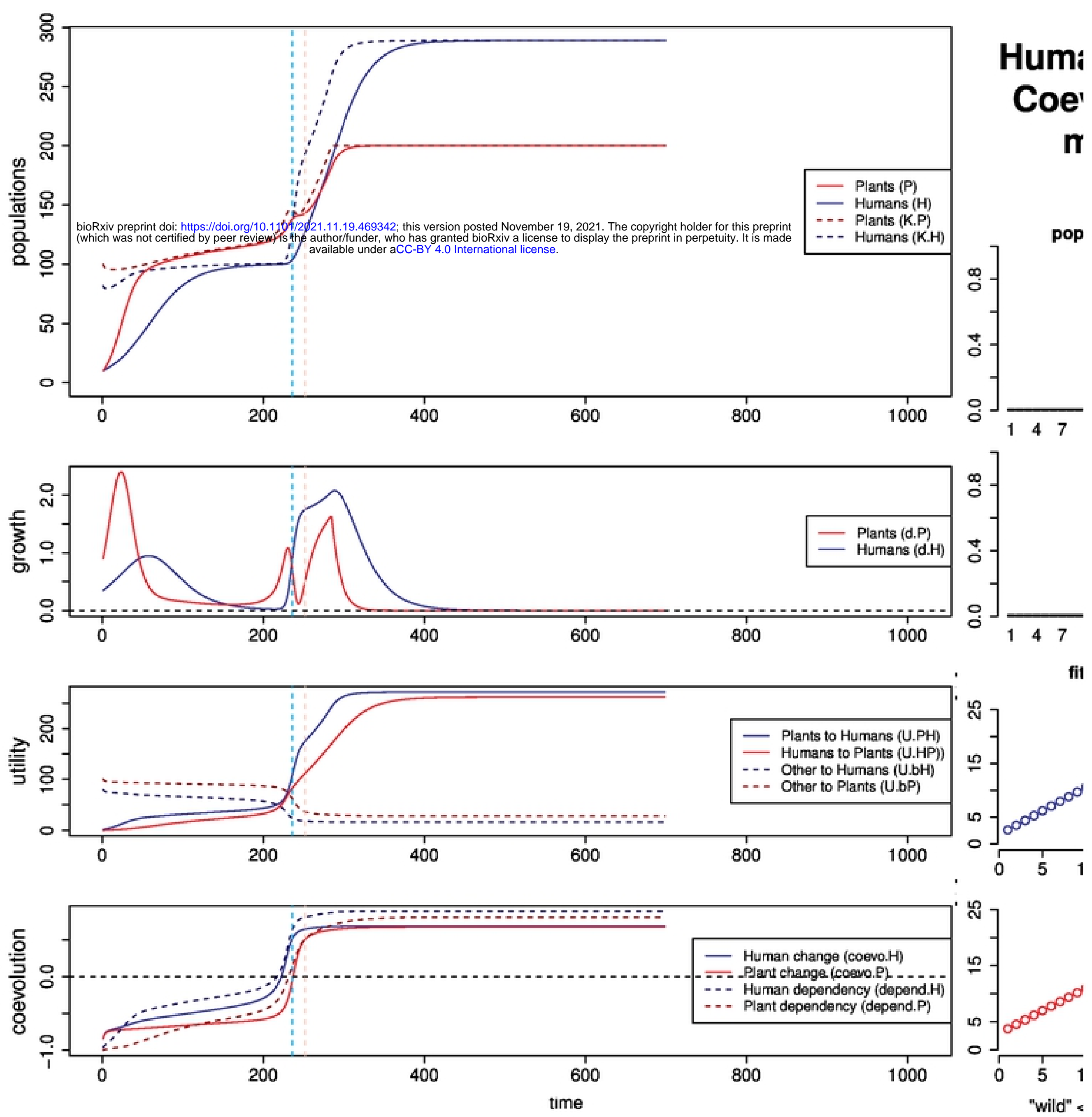

\section{Parameter setting:}

iniH $=10$, iniP $=10, n . H=30, n . P=30, v \cdot H=0.15, v . P=0.15, r . H=0.04, r . P=0.1, m U . P n H=1.5, m U . H n P=1, m U . P 1 H$ $\mathrm{mU} \cdot \mathrm{H} 1 \mathrm{P}=0, \mathrm{U} \cdot \mathrm{bHn}=10, \mathrm{U} \cdot \mathrm{bPn}=20, \mathrm{U} \cdot \mathrm{bH} 1=80, \mathrm{U} \cdot \mathrm{bP} 1=100, \mathrm{MaxArea}=200$, maxlt $=5000$, tol $=6$, timing.threshold 


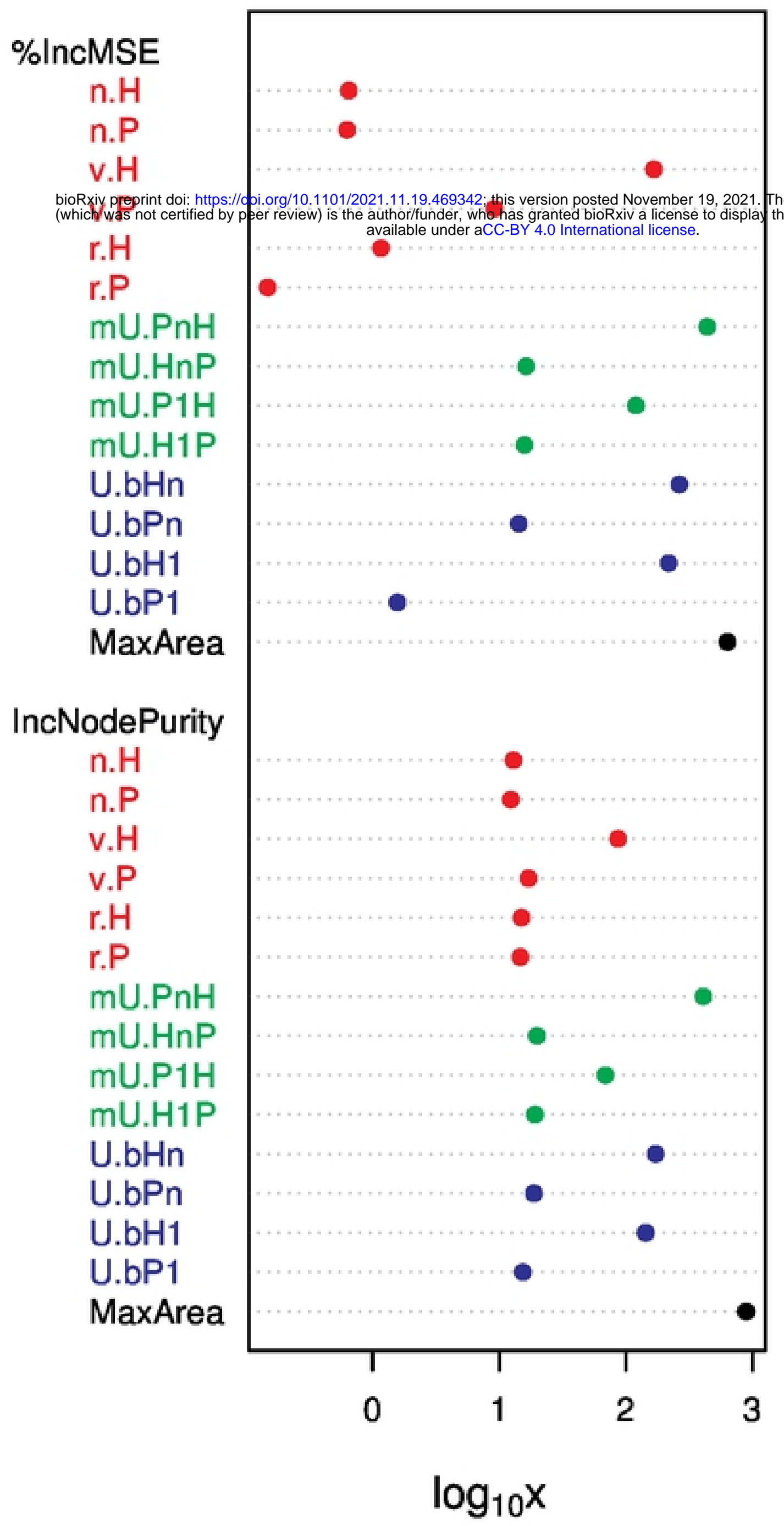

\section{\%IncMSE \\ n. $\mathrm{H}$ \\ n.P \\ v.H}

Rxiy preprint doi: https://goi.org/10.1101/2021.11.19.469342; this version posted November 19, 2021. The copyright holder for this preprint

r.H

r.P

mU.PnH

U.bHn

U.bPn

U.bH1

U.bP1

MaxArea

n.H

n.P

P

r.H

r.P

$\mathrm{mU} . \mathrm{PnH}$

$\mathrm{mU} . \mathrm{HnP}$

mU.P1H

mU.H1P

U.bHn

U.bPn

U.bH1

U.bP1

MaxArea
r.H

r.P

mU.PnH

mU.HnP

mU.P1H

mU.H1P

U.bHn

U.bPn

U.bH1

U.bP1

MaxArea

IncNodePurity

n.H

n.P

v.H

v.P

r.H

r.P

mU.PnH

$\mathrm{mU} . \mathrm{HnP}$

mU.P1H

mU.H1P

U.bHn

U.bPn

U.bH1

U.bP1

MaxArea

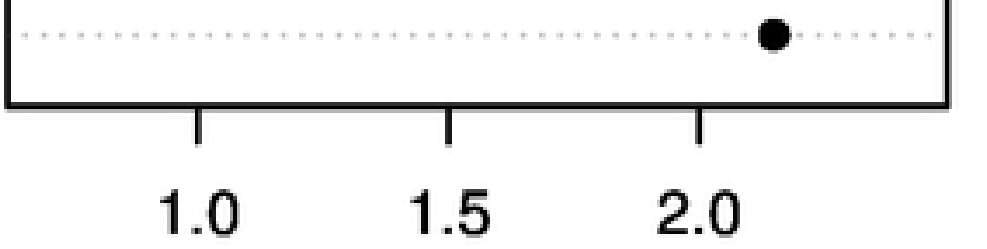

$\log _{10} x$ 
